\title{
Balıkesir İli İçin Hayvansal Atık Kaynaklı Biyogaz Potansiyelinin Belirlenmesi
}

\author{
Süreyya Kocabey ${ }^{1 *}$ \\ ${ }^{1}$ Sağlık Bilimleri Üniversitesi, Hamidiye Sağlık Hizmetleri Meslek Yüksekokulu, Elektronik ve Otomasyon Bölümü, İstanbul, Türkiye (ORCID: 0000-0002-2300- \\ 0789)
}

(İlk Geliş Tarihi 12 Eylül 2019 ve Kabul Tarihi 14 Ekim 2019)

(DOI: 10.31590/ejosat.619058)

ATIF/REFERENCE: Kocabey, S. (2019). Balıkesir İli İçin Hayvansal Atık Kaynaklı Biyogaz Potansiyelinin Belirlenmesi. Avrupa Bilim ve Teknoloji Dergisi, (17), 234-243.

\begin{abstract}
$\ddot{O} \mathbf{z}$
Günümüzde dünya genelinde enerjiye duyulan ihtiyacın sürekli artması ülkeleri yeni enerji kaynakları arayışına itmiştir. Ülkelerin bu yeni enerji kaynağı arayışları esnasında; fosil enerji kaynaklarının sınırlı rezerve sahip olması ve olumsuz çevresel etkileri, enerji arz güvenliğinin stratejik öneme sahip olması ve ülkelerin enerjide dışa bağımlılıktan kurtulmak istemesi gibi sebepler yenilenebilir enerji kaynaklarına olan ilgiyi arttırmıştır. Ülkemiz fosil enerji kaynak rezervlerine yakın olmasına rağmen enerji ihtiyacımızın \% 75 'i ithal yollarla temin edilmektedir. Coğrafi bölgemiz ekseninde ortaya çıkan siyasal krizler ve savaşlar enerji arz güvenliğimizi tehdit eder hale gelmiştir. Bu kapsamda dışa bağımlılıktan kurtulmak ve elektrik üretim kaynaklarımızın çeşitlendirilmesi amacıyla yerli enerji kaynaklarımızın potansiyellerinin araştırılması gerekmektedir. Bu çalışmada, Balıkesir il sınırları içerisindeki büyükbaş, küçükbaş ve kümes hayvanlarından kaynaklanan hayvansal atıklardan elde edilebilecek biyogaz potansiyelinin belirlenmesi amaçlanmıştır. Hayvan sayılarının belirlenmesinde 2018 yılı Türkiye İstatistik Kurumu (TÜIK) verilerinden faydalanılmıştır. Yapılan hesaplamalar sonucunda Balıkesir ilinde yıllık $390.114 .719 \mathrm{~m}^{3}$ biyogaz potansiyeli olduğu belirlenmiştir. Bu biyogaz potansiyelinin \%51'i büyükbaş hayvanlardan, \%6'sı küçükbaş hayvanlardan ve \%43'ü kümes hayvanlarından elde edilebilir. Halihazırda hayvansal atık kullanarak elektrik üreten biyogaz elektrik santralleri (BES) Gönen, Bandırma gibi kuzeydeki ilçelerin sınırlarında bulunmaktadır. Kurulu ve inşa halindeki santraller ile birlikte Balıkesir ilindeki hayvansal atık kaynaklı BES'lerin toplam gücü 10,30 MW'a ulaşacaktır. Yıllık 390.114.719 $\mathrm{m}^{3}$ biyogazın eşdeğer elektrik enerjisi potansiyeli 893.363 MWh'dir. Bu toplamda $112 \mathrm{MW}$ kurulu güce sahip BES kurulabileceği anlamına gelir. Mevcut santraller ile biyogaz potansiyelinin ancak \%10'u kullanılabilir durumdadır. Dolayısıyla Balıkesir ilinde yaklaşık 102 MW daha BES kurulabilme potansiyeli vardır. Hayvansal atıkların aynı zamanda bir çevresel sorun olduğu düşünüldüğünde hayvan yoğunluğunun yüksek olduğu ve büyük ölçekli hayvan çiftliklerinin bulunduğu ilçelerde BES kurulması yönünde teşviklerin yapılması gereklidir.
\end{abstract}

Anahtar Kelimeler: Balıkesir, Biyogaz, Yenilenebilir enerji, Hayvansal atıklar, Atık bertaraf.

\section{Determination of Biogas Potential from Animal Waste for Balıkesir Province}

\begin{abstract}
Today, the continuous increase in the need for energy around the worldwide has led countries to seek new energy sources. During the countries' search for this new energy sources; limited reserves and negative environmental impacts of fossil energy sources, the strategic importance of energy supply security and the desire of countries to get rid of dependence on foreign energy, increased the
\end{abstract}

\footnotetext{
* Sorumlu Yazar: Sağlık Bilimleri Üniversitesi, Hamidiye Sağlık Hizmetleri Meslek Yüksekokulu, Elektronik ve Otomasyon Bölümü, İstanbul, Türkiye, ORCID: 0000-0002-2300-0789, sureyya.kocabey@ sbu.edu.tr
} 


\section{European Journal of Science and Technology}

interest in renewable energy sources. Although our country is located close to fossil energy reserves, $75 \%$ of our energy needs are supplied by imported means. In recent years, political crises and wars in our region have become a threat to our energy supply security. In this context, in order to get rid of external dependence and to diversify our electricity generation resources, the potentials of our domestic energy resources should be investigated. In this study, it is aimed to determine the biogas potential that can be obtained from animal wastes from cattle, small ruminants and poultry in the Balikesir province. In determining the number of animals, it has been benefited from the Turkey Statistical Institute (TSI) 2018 data. As a result of the calculations, it has been determined that there is an annual biogas potential of $390.114 .719 \mathrm{~m}^{3}$ in Balıkesir province. The available biogas potential can be obtained from $51 \%$ cattle, $6 \%$ from small ruminants and $43 \%$ from poultry. Currently, Biogas Power Plants (BPP) that generate electricity using animal wastes in Balıkesir province are located in the northern districts such as Gönen and Bandırma. The total power of the BPPs utilizing animal waste resources in Balıkesir province will be 10,30 MW with the installed and under construction power plants. The equivalent electrical energy potential of $390.114 .719 \mathrm{~m}^{3}$ biogas per year is $893,363 \mathrm{MWh}$. This means that BPP with totally $112 \mathrm{MW}$ installed power can be installed. Only $10 \%$ of the Balıkesir's total biogas potential is available with the existing power plants. Therefore, in Balıkesir province, there is a potential to be established for about $102 \mathrm{MW}$ of BPP. Considering that animal wastes are also an environmental problem, incentives by the state should be made for the establishment of BPP in districts with high animal density and large-scale animal farms.

Keywords: Balıkesir, Biogas, Renewable energy, Animal wastes, Waste disposal.

\section{Giriş}

Enerji günümüzde dünya kamuoyunu en çok meşgul eden gündem maddelerinden biridir. Bunun en başta gelen nedeni globalleşme, nüfus artışı ve artan endüstriyel üretim ile birlikte ülkelerin büyüyen enerji ihtiyacıdır. Uluslararası Enerji Ajansı'na (UEA) göre, 2035'e kadar global enerji talebinin bugüne göre \%47 artması beklenmektedir (Suganthi ve Samuel, 2012; Magistretti ve ark., 1999; WEC, 2013). Dünya genelinde artan bu enerji talebine cevap vermek ve enerjide dışa bağımlılığı azaltmak için yeni enerji kaynak arayışları hız kazanmıştır. Bu kapsamda, fosil yakıtların tükenmekte olması ve çevreye olan olumsuz etkileri yenilenebilir enerji kaynaklarına ülkelerin enerji politikalarında öncelik verilmesine yol açmıştır.

Gelişmiş ülkelerin uyguladıkları sanayi politikalarına bakıldığında, büyüme ve sanayileşmenin ucuz, kesintisiz ve dışa bağımlı olmayan enerjiden geçtiği görülmektedir. 2011 yılında Türkiye Sanayici ve İş Adamları derneği (TÜSİAD) tarafindan yayınlanan Vizyon 2050 Türkiye raporunda, Türkiye'nin ekonomik ve sosyal refahını sürdürülebilir kılmak için düzenli olarak yıllık \%5-6 büyümesi gerektiği söylenmektedir. Halihazırda ülkemizdeki mevcut enerji tüketiminin yaklaşı \% $\% 75$ 'inin ithalat yolu ile karşılandığı gözönüne alındığında yenilenebilir enerji kaynaklarının önemi daha kolay anlaşılacaktır (TÜSİAD, 2011). Ayrıca son yıllarda dünya siyasetinde yaşanan olaylar ülkemiz açısından enerji arz güvenliğinin ne kadar önemli olduğunu bir kez daha ortaya koymuştur. Bu doğrultuda enerji kaynaklarımızın çeşitlendirilmesi, yerli enerji kaynaklarımızın kullanıma sunulması ve enerji alanında teknolojilerin geliştirilmesi ülkemizin geleceği için büyük önem arz etmektedir.

Ülkemizde yerli enerji kaynaklarımız olarak rüzgar, güneş, linyit, hidroelektrik ve biyokütle enerjilerini sayabiliriz. Biyokütle enerjisi, hayvansal atıklar ve ormansal ve tarımsal kalıntılardan oluşan bir yenilenebilir enerji kaynağıdır (McKendry, 2002). Biyokimyasal dönüşüm süreci, ABD enerji bakanlığı tarafından organik malzemelerin yakıta dönüşmesi için canlı organizmalar veya onların ürünlerinin kullanımı şeklinde tanımlanmıştır (Cantrell ve ark., 2012). Dolayısıyla, biyokütleden enerji üretimi biyogaz üretim teknolojisine bağlı olarak çevre dostu bir yöntemdir denilebilir. Biyogaz yüksek ssıl verimliliğe sahip, temiz ve yerel bir enerji kaynağıdır. Bugüne kadar dünya genelinde biyogaz neredeyse tamamiyle elektrik ve isı üretiminde kullanılmaktadır (Solomie ve ark., 2010).

Türkiye Elektrik İletim A.Ş. (TEİAŞ) tarafından 2018 yılı Mayıs ayında yayınlanan "Türkiye Elektrik Enerjisi 5 Yıllık Üretim Kapasite Projeksiyonu" raporunda Türkiye'deki biyokütle santralleri kurulu güç kapasitesi (atık 1s1 ve çöp dahil) 2017 sonu itibariyle 634 MW, 2018 sonu itibariyle 675 MW, 2019 sonunda 715 MW, 2022 sonuna kadar toplamda 775 MW kapasiteye ulaşması öngörülmüştür. Ancak halihazırda 2019 başı itibariyle 738,8MW kapasiteye ulaşılarak bu öngörülerin üzerine çıkılmıştır (TEİAŞ, 2018). Enerji ve Tabii Kaynaklar Bakanlığı tarafından hazırlanan Türkiye Biyokütle Enerjisi Potansiyel Atlasına göre Balıkesir ilinde biyokütle kaynaklı lisanslı 3 adet toplamda 35,75 MW biyokütle elektrik santrali bulunmaktadır. Bu 3 santraldan sadece 2 tanesi hayvansal atık kullanmaktadır ve toplamda 5,75 MW kurulu güce sahiptir (ETKB, 2019). Güney Marmara Kalkınma ajansı tarafından yayınlanan 2017 yılı eylem raporunda ise Balıkesir genelinde biyogaz ve biyokütle tesisi sayısının 2023 'te 10 adete ulaştırılması hedeflenmektedir (GMKA, 2017).

Balıkesir bütün hayvan türleri sayısında ve hayvansal ürünlerin üretiminde Türkiye'de ilk 5 il arasında yer almaktadır. Bu kadar büyük hayvan yoğunluğuna sahip olması, hayvansal kaynaklı atıkları il genelinde bir çevre sorunu olarak karşımıza çıkarmaktadır. Halihazırda hayvansal atıklar tarlalara doğal gübre olarak atılarak bertaraf edilmektedir. Bu şekilde atılan atıklardan kontrolsüz bir şekilde atmosfere karışan metan gazı küresel ısınma noktasında karbondioksite göre 30 kat daha fazla zararlı etkiye sahiptir (Sözer ve Yaldız, 2011). Biyogaz yakıldı̆̆ında, metan gazının atmosfere salınımına engel olarak sera etkisinin azaltılmasına katkıda bulunur (Gülen ve Arslan, 2005; Wuebbles, 2002; Montzka ve ark., 2011). Bu sebeple, biyogaz elektrik santralleri (BES) büyük ölçekli hayvan çiftliklerinin atıklarının bertaraf edilmesine de yardımcı olurlar.

Yapılan bu çalışma kapsamında, hayvancılıkta alanında ülkemizin önde gelen illerinden olan Balıkesir'in hayvansal kaynaklı biyogaz enerji potansiyeli araştırılmıştır. Elde olunan sonuçlar ışı̆̆ında atıkların bertarafı konuları dikkate alınarak BES kurulabilecek bölgeler tespit edilmiştir. 


\section{Materyal ve Metot}

Bu çalışmada 2018 yılına ait Balıkesir ilindeki hayvan varlığına dair bilgiler TÜiK ve İl Tarım ve Hayvancılık müdürlüğü verilerinden alınmıştır. Daha sonra Balıkesir ilinin ilçelere göre hayvan dağılımı analiz edilmiştir. Biyogaz potansiyelini, toplanabilecek toplam yaş atık miktarı ve bunların biyogaz üretebilme kapasiteleri belirlemektedir. Bu kapsamda yapılan literatür araştırmaları ve biyogaz üretim sürecinde yapılacak hesaplamalara ilişkin detaylar aşağıda verilmiştir.

\subsection{Biyogaz Özellikleri}

Biyogaz bitkisel, hayvansal, şehir ve endüstriyel atıkların anaerobik fermantasyonu sonucu ortaya çıkan bir gaz türüdür. Bileşiminde organik maddelerin bileşimine bağlı olarak yaklaşı; \% \%0-70 metan, \%30-60 karbondioksit, \%0-3 hidrojen sülfür ile çok az miktarda azot ve hidrojen bulundurur. İçeriğindeki metan gazından dolayı yanabilme özelliğine sahiptir. Biyogazın 1sıl eşdeğeri metan oranına bağlı olarak 20-25 MJ/m³ tür (Bond ve Templeton, 2011; Çağlayan ve Koçer, 2014).

Anaerobik fermantasyon sürecinde metan oluşumunu sağlayan metan bakterileri, fermantasyon ortamının sıcaklığına göre üç gruba ayrılırlar. Bunlar sakrofilik, mezofilik, termofilik fermantasyondur. Metan bakterilerinin büyümesi için optimum sıcaklık aralıkları sirasıyla $5-25{ }^{\circ} \mathrm{C}, 30-40{ }^{\circ} \mathrm{C}$ ve $50-62{ }^{\circ} \mathrm{C}$ dir (Ogejo ve ark., 2009). Ortam sıcaklığı, metan gazı üretiminde en önemli etmendir. Metan bakterileri ani sıcaklık değişimlerinden, gece-gündüz sıcaklık farkından kolaylıkla etkilenirler. Bu sebeple üreteç iç sıcaklığının sabit tutulması amacıyla biyogaz yakma motorunun soğutma suyundan faydalanılır. Üreteç içindeki bakteriler $4,5-75^{\circ} \mathrm{C}$ sıcaklık aralıklarında metan gazı üretebilirler (Yaldız ve ark., 1998). Bu nedenle sıcak bölgelerde biyogaz üretim tesislerinin başarısı oldukça yüksektir. Büyükbaş hayvan atıklarında katı madde oranı \%13-20 civarındadır. Ancak optimum biyogaz oluşumu için üreteç içindeki atık-su karışımın katı madde oranının \%7-9 olması gerekmektedir. Bu amaçla biyogaz üretim sürecinde üreteç içine konulan hayvansal atıklar seyreltilir (Abade ve ark., 2015).

Biyogaz üretim sürecinde antibiyotik almış hayvanların atıklarının üretim tankına alınmaması biyogaz üretim başarısı için birincil önceliktir. Çünkü Büyükbaş hayvancılık sektöründe kullanılan antibiyotiklerin \%17 -\%90 arası hayvan dışkıları ile dışarı atılır. Bunun anlamı eğer hayvanlarda antibiyotik kullanılırsa bu ilaçlar hayvan atıklarında hala varlıklarını devam ettirirler (Massé ve ark., 2014). Antibiyotikler, biyogaz verimini düşürdüğ̈̈ gibi, biyogazın metan içeriğinde de azalmaya yol açmaktadır. Azalma seviyesi antibiyotik cinsine, gübrenin konsantrasyonuna ve tank içindeki üretim süresine göre değişmektedir. Sonuç olarak, bir önceki duruma göre antibiyotik karıştırıldığında elde edilen metan miktarlarında \%10 ile \%33 arasında değişen oranlarda azalma meydana gelmektedir (El-Din, 1986). Dolayısıyla üreticilerin bilinçlendirilerek antibiyotik kullanan hayvanları diğer hayvanlardan ayrı depolaması ve ahırlarda temizlik vb işlerde kimyasallar kullanmamaya özen göstermesi sağlanmalıdır.

Anaerobik fermantasyon sürecinde biyogaz üretiminin başarısı için aşağıdaki hususlara dikkat edilmesi gerekir (Çağlayan ve Koçer, 2014 ; Yaldız ve ark., 1998; Yılmaz, 2019).

- Fermantör-Üreteç içinde kesinlikle oksijen bulunmamalı,

- Üreteçe 1şık girmemeli ve ortam karanlık olmalı,

- Antibiyotik almış hayvanlara ait atıklar üretim tankına alınmamalı,

- Deterjanlı organik atıklar üretim tankına alınmamalı,

- Üretim yöntemine göre üreteç iç sıcaklığı 35 veya $56^{\circ} \mathrm{C}$ de sabit tutulmalı,

- Uygun karbon azot oranı sağlanmalı $(\mathrm{C} / \mathrm{N})$,

- Ortam asitliği (pH) 6.8-7.8 arasında olmalı,

- Üreteçteki hammadde seyreltilmeli,

- İdeal fermentasyon süresi sağlanmalıdır.

\section{2. Çalışma Alanı}

Balıkesir yüzölçümü $14.299 \mathrm{~km}^{2}$ (göller dahil hariç) olup coğrafi olarak Türkiye'nin batısında $39,20^{\circ}$ - 40,30 enlemleri ve $26,30^{\circ}-28,30^{\circ}$ boylamları arasında yer alır. Doğuda Bursa ve Kütahya illeri, güneyde Manisa ve İzmir illeri ve batıda Çanakkale ili ile komşudur. İlin kuzey yöndeki en uç noktası güneydekine $175 \mathrm{~km}$, doğu yöndeki en uç noktası batısındakine $210 \mathrm{~km}$ uzaklıktadır. Şekil 1'de görüldüğü üzere Balıkesir siyasi olarak büyükşehir belediyesi olup merkez ilçeleri ile birlikte toplam 20 ilçeye sahiptir. İlin topraklarının büyük bir kısmı Marmara Bölgesi'nde, geri kalan kısmı da Ege Bölgesi'ndedir. Hem Marmara hem de Ege Denizi'ne kıyısı bulunmaktadır (BBB, 2019).

İlin düzlük yerleri olduğu kadar dağlık kısımları da vardır. İlin en yüksek noktası 2.089 metre ile Dursunbey ilçesinde bulunan Akdağ tepesidir. İlin topraklarının \%27,21'i tarım alanı, \%5,66'sı çayır-mera alanı, \%22,28'i tarım dışı alan ve \% 44,85'ini ormanlar kaplamaktadır (BBB, 2019). Balıkesir, coğrafi yapısı ve iklim koşulları ile bir tarım kentidir. Verimli tarım arazilerinin yaygın olarak bulunduğu Balıkesir, sahip olduğu stratejik konum ile tarımsal ürünlerini kolayca pazarlama olanağına sahiptir. Yatırımların dağılımına bakıldığında ekonomik büyüklük bakımından baskın sektörün \%64 oranla tarım ve hayvancılık olduğu görülmektedir (GMKA, 2019).

Sanayileşmenin çok yoğun olduğu Marmara Bölgesi'nde yer alan Balıkesir, entansif (endüstriyel) süt ve besi işletmelerinin önemli bir kısmını barındırmaktadır. Balıkesir genelindeki sığırların \%7'si yerli, \%71'i kültür \%22'si melez sığırdır (TÜIK, 2019). Dolayısıyla büyükbaş hayvan varlığı et, süt ve atık verimi çok yüksek hayvanlardan oluşmaktadır. İl genelindeki sığırların yaklaşık \%44'ü 20 baş altında sığıra sahip aile işletmelerinde bulunmaktadır. Balıkesirin hemen her ilçesinde 20 baş ve üzeri hayvan varlığına 
sahip ölçekte işletmeler bulunmaktadır. Bu ölçekte işletmelerde günlük yaklaşık 1 ton yaş gübre üretilmektedir. Küçükbaş hayvanların \%49’u 100 baş ve üzeri hayvana sahip işletmelerde bulunmaktadır. Balıkesir genelinde ilçelerin çoğunluğunda 100 baş ve üzeri hayvan sayısı yoğunluğu \%40’ın üzerindedir. Hemen her ilçede küçükbaş atık potansiyeli mevcuttur. 2018 yılı itibariyle il genelinde toplam 726 adet entegre broiler, 77 adet yumurta tavukçuluk işletmesi bulunmaktadır (TÜİK, 2019; GMKA, 2012).

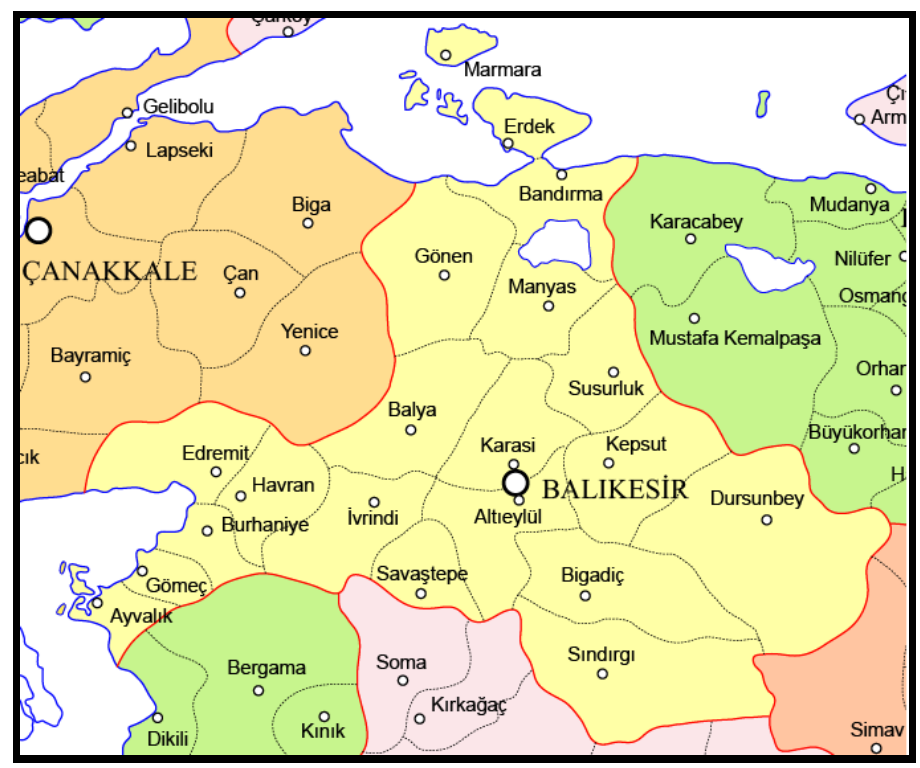

Şekil 1. Balıkesir İli ve İlçeleri Mücavir Sınırları

\subsection{Hayvan Sayıları}

Büyükbaş hayvan olarak manda dışındaki sığırlar, küçükbaş hayvan olarak koyun ve keçi, kümes hayvanı olarak da broiler tavuğu, yumurta tavuğu, hindi ve ördek sayıları referans alınmıştır. 2018 yılı TÜİK verilerine göre Balıkesir genelindeki hayvan sayısı Tablo 1'de verilmiştir (TÜİK, 2019). 
Tablo 1. 2018 Yılı İtibariyle Balıkesir Il Genelindeki Hayvan Sayıları

\begin{tabular}{|c|c|c|c|c|c|c|c|}
\hline \multirow[b]{2}{*}{ İlçe Adı } & \multicolumn{5}{|c|}{ Kümes hayvanları } & \multirow{2}{*}{$\begin{array}{c}\text { Büyükbaş } \\
\text { (Manda hariç) }\end{array}$} & \multirow{2}{*}{$\begin{array}{c}\text { Küçükbaş } \\
\text { (Koyun / Keçi) }\end{array}$} \\
\hline & $\begin{array}{c}\text { Tavuk } \\
\text { (Broiler tek dönem) } \\
\end{array}$ & $\begin{array}{c}\text { Tavuk } \\
\text { (Yumurta) }\end{array}$ & Hindi & Ördek & Toplam & & \\
\hline Altteylül & 2.959 .975 & 716.429 & 3.264 & 890 & 3.680 .558 & 74.375 & 133.600 \\
\hline Ayvalık & 0 & 15.500 & 60 & 65 & 15.625 & 6.800 & 27.911 \\
\hline Balya & 25.200 & 127.280 & 200 & 30 & 152.710 & 25.320 & 58.900 \\
\hline Bandirma & 4.766 .140 & 3.371 .654 & 250 & 307 & 8.138 .351 & 16.291 & 32.740 \\
\hline Bigadiç & 2.375 .527 & 75.500 & 0 & 0 & 2.451 .027 & 79.650 & 57.930 \\
\hline Burhaniye & 457.000 & 285.000 & 470 & 190 & 742.660 & 12.618 & 37.500 \\
\hline Dursunbey & 730.355 & 9.680 & 800 & 230 & 741.065 & 25.878 & 79.308 \\
\hline Edremit & 70.000 & 2.795 & 137 & 95 & 73.027 & 7.535 & 13.082 \\
\hline Erdek & 1.782 .632 & 14.500 & 90 & 80 & 1.797 .302 & 4.313 & 9.357 \\
\hline Gömeç & 0 & 1.300 & 10 & 30 & 1.340 & 1.434 & 13.689 \\
\hline Gönen & 1.395 .000 & 393.000 & 409 & 2.638 & 1.791 .047 & 41.141 & 95.096 \\
\hline Havran & 0 & 5.160 & 59 & 265 & 5.484 & 15.449 & 23.534 \\
\hline Karesi & 3.791 .788 & 13.400 & 2.400 & 107.508 & 3.915 .096 & 43.548 & 132.309 \\
\hline Kepsut & 121.000 & 14.151 & 255 & 40 & 135.446 & 29.012 & 49.890 \\
\hline Manyas & 729.220 & 1.402 .496 & 296 & 2.694 & 2.134 .706 & 24.560 & 64.762 \\
\hline Marmara & 0 & 550 & 30 & 50 & 630 & 1.001 & 11.947 \\
\hline Savaştepe & 2.068 .759 & 282.000 & 270 & 190 & 2.351 .219 & 15.450 & 28.410 \\
\hline Susurluk & 1.763 .973 & 101.061 & 62.541 & 873 & 1.928 .448 & 35.447 & 88.526 \\
\hline Sindirgl & 1.324 .000 & 16.000 & 89 & 164 & 1.340 .253 & 30.995 & 104.000 \\
\hline Ivrindi & 1.800 .000 & 20.980 & 816 & 319 & 1.822 .115 & 47.865 & 127.363 \\
\hline TOPLAM & 26.160 .569 & 6.868 .436 & 72.446 & 116.658 & 33.218 .109 & 538.682 & 1.189 .854 \\
\hline
\end{tabular}

Balıkesir ilinde, büyükbaş hayvan varlığının en yüksek olduğu ilçe 117.923 adet hayvan ve \%21,9'lik oran ile Merkez Altıeylül ve Karesi ilçeleri, en az olduğu ilçe 1.001 adet hayvan ve \%0,18'lik oran ile Marmara ilçesidir. Balıkesir ilinde küçükbaş hayvan varlığının en yüksek olduğu ilçe 265.909 adet hayvan ve \%22,3'lük oran ile Merkez Altıeylül ve Karesi ilçeleri, en az olduğu ilçe 9.357 adet hayvan ve \%0,78'lik oran ile Erdek ilçesidir. Balıkesir ilinde kümes hayvan varlığının en yüksek olduğu ilçe 8.138.351 adet hayvan ve \%24,4'lük oran ile Bandırma ilçesi, en az olduğu ilçe 630 adet hayvan ve \%0,002'lik oran ile Marmara ilçesidir.

Balıkesir 2018 İl Tarım ve Orman Müdürlüğü verilerine göre Türkiye genelindeki iller arasında, büyükbaş hayvan sayısında 5.sırada, koyun sayısında 3.sıradadır. Kümes hayvanı sayısı için ördek sayısında 1., et tavuğu sayısında 3., yumurta tavuğu sayısında 5., hindi sayısında ise 8. sirada bulunmaktadır (BİTOM, 2019).

\subsection{Kullanılan Kabuller}

Bilindiği üzere gübre üretimi hayvanların beslenme yoğunluğuna ve besin türüne, su içme sıklığına göre çok değişken olabilir. Bu çalışmada Balıkesir ilinin biyogaz potansiyelinin hesaplanması için daha önceki literatür çalışmaları incelenmiştir. Bu çalışmalardan elde edilen sonuçlara göre gübre miktarı, biyogaz potansiyeli ve bunun elektriksel eşdeğeri hesaplanmasında bazı kabuller kullanılmıştır. ABD tarım bakanlığı tarafından yayınlanan raporda bir çiftlik hayvanı canlı ağırlığının yaklaşık \%6-8'i kadar gübre üretebilir denilmektedir (NRCS, 2019a; ASAE, 2005).

Sı̆̆ırların gübre üretim potansiyeli cinsine (yaş), cinsiyetine, kilosuna ve beslenme türüne bağlıdır. Genelde sığırlar için literatürde canlı ağırlığının \%6-10 arasında yaş gübre üretir denilmektedir. Buradan hareketle boğalar, tosunlar, düveler ve buzağılar sırasıyla günlük $42 \mathrm{~kg} /$ gün, $37 \mathrm{~kg}$ /gün, $24 \mathrm{~kg} /$ gün, $12 \mathrm{~kg} /$ gün yaş gübre üretirler. Bir süt verebilen inek günlük canlı ağırlığının \%8-10 kadar yaş gübre üretebilir. Bu rakam yaklaşık 48-68 kg/gün'e karşılık gelir (ASAE, 2005; Division, 2019). Buradan hareketle büyükbaş hayvanlarda yaş gübre üretim miktarı olarak inek, boğa, tosun, düve ve buzağılar sırasıyla günlük $58 \mathrm{~kg} / \mathrm{gün}, 42 \mathrm{~kg} / \mathrm{gün}, 37$ $\mathrm{kg} /$ gün, $24 \mathrm{~kg} /$ gün, $12 \mathrm{~kg} /$ gün alınacaktır.

Günümüzde Balıkesir ilinde büyükbaş hayvancılık \%93 gibi yüksek bir rakamla kültür ve kültür melezi ırklar üzerinden ve kapalı ahırlarda yapılmaktadır (TÜİK, 2019). Bu işle uğraşan kişilerin yaş ortalamasının yüksek olması, mera alanlarının hızla azalması, hayvan türlerinin yüksek ağırlığa ve süt verimine sahip kültür ırkı olmasından dolayı büyükbaş hayvancılık faaliyetlerinde meracılık faaliyetleri neredeyse yok olmuştur (Straße ve Ertem, 2011). Ayrica büyük ölçekli hayvan çiftliklerinde de hayvanlar mevsim e-ISSN: 2148-2683 
koşullarına bağlı olarak tesisin yakınındaki kendi özel arazisinde otlatılmaktadır. Literatürde sürekli otlatma, kısıtlı süreli otlatma ve sürekli barınakta bakılma durumlarına göre elde olunacak gübre hesaplamaları yapılmıştır. Kısıtlı süreli otlatmada $\% 67$ ve sürekli barınakta bakılmada \%100 gübre elde edilebileceği kabul edilmiş̧ir. Yukarıdaki sebeplerden ötürü Balıkesir ilindeki büyükbaş hayvanlardan elde edilecek toplam yaş gübre miktarı hesabında yukarıdaki iki değerin ortalaması alınarak \%84 geri kazanıldığı kabul edilecektir (NRCS, 2019b; SN, 2012).

Türkiye içerisindeki koyun türlerinin canlı ağırlığı 40-60 kg aralığındadır (EIDKKYB, 2019). Koyun canlı ağırlığının \%4'ü kadar günlük yaş gübre üretimi söz konusudur. $50 \mathrm{~kg}$ bir koyun için bu rakam günlük yaklaşı $2 \mathrm{~kg} /$ gün'dür. Yavru küçcükbaş hayvanlar için yetişkinlerin \%60'ı kadar gübre ürettiği kabul edilecektir. Keçi için de aynı kabuller kullanılacaktır (SN, 2012). Literatürde küçükbaş hayvanlar için elde edilebilir gübre oran1 \%13 verilmektedir (Salihoğlu ve ark., 2019; Kaya ve ark., 2009; Başçetinçelik ve ark., 2003; Ekinci ve ark., 2010). Ancak Balıkesir ilinde hayvanlar mevsimsel koşullar izin verdiği sürece yaz kış günde 9-12 saat meraya çıkarılmaktadır. Dolayısıyla hayvanların günlük 12-15 saati ahılda geçmektedir. Buradan hareketle elde edilmesi muhtemel yaş gübre oranı $\% 50$ olarak alınacaktır.

Kümes hayvanları için \%99 gübre elde edilebilirlik oranı kabul edilecektir (Kaya ve ark., 2009; Başçetinçelik ve ark., 2003). Sirasıyla broiler tavuğu, yumurta tavuğu, hindi ve ördek için $0,19 \mathrm{~kg}, 0,13 \mathrm{~kg}, 0,38 \mathrm{~kg}$ ve $0,33 \mathrm{~kg}$ yaş gübre ürettikleri referans alınmıştır (Ekinci ve ark., 2010).

Besi hayvanları, et tutmayı olumsuz etkilediği için meraya çıarılmamaktadır. Dolayısıyla onlar için elde edilebilir gübre oranı \%100’dür. Bu çalışmada farklı hayvan türleri için yaş gübre hesabında bu durum dikkate alınmamıştır.

Biyogaz verimi üreteç iç sıcaklı̆ı̆na, yükleme oranına ve kısım 2.1'de verilen pekçok değişkene bağlıdır. Literatür bilgilerine göre 1 ton uçucu katı maddeden (UKM) sırasıyla inek, et sığırı, küçükbaş ve kümes hayvanları için $180 \mathrm{~m}^{3}, 330 \mathrm{~m}^{3}, 300 \mathrm{~m}^{3}$ ve $350 \mathrm{~m}^{3}$ biyogaz elde edilebilir (Ekinci ve ark., 2010). Dolayısıyla 1 ton yaş sığır gübresinden yılda $33 \mathrm{~m}^{3}, 1$ ton yaş küçükbaş gübresinden ise yılda $58 \mathrm{~m}^{3}, 1$ ton yaş kümes hayvanı gübresinden yılda $78 \mathrm{~m}^{3}$ biyogaz elde edileceği kabul edilmiştir (Kaya ve ark., 2009; Bayrak Isik ve Polat, 2018; EIGGM, 2019).

Biyogazın \%50-\%70'i metan gazıdır. Bileşimindeki metan oranına göre 1sıl değeri 20-25 MJ $/ \mathrm{m}^{3}$ arasında değişmektedir (Bond ve Templeton, 2011). Bu sebeple $1 \mathrm{~m}^{3}$ biyogazın 1 ssıl eşdeğeri $22,5 \mathrm{MJ} / \mathrm{m}^{3}$ kabul edilmiştir. $22,5 \mathrm{MJ}$ 1sıl enerjinin elektrik enerjisi eşdeğeri 6,11 kWh'tir. Ancak biyogazdan elektrik enerjisi üretimi kojenerasyon sistemi ile yanma enerjisinin mekanik enerjiye dönüşümü yoluyla yapılmaktadır. Kojenerasyon santrallerinin elektriksel verimi de \%35-40 aralığında değişmektedir. \%37,5 verime sahip bir kojenerasyon santralı için $1 \mathrm{~m}^{3}$ biyogazın elektriksel eşdeğeri 2,29 $\mathrm{kWh}$ olarak kabul edilecektir. Biyogaz potansiyeli hesaplamasında kullanılacak kabuller Tablo 2'de birarada verilmiştir.

Tablo 2. Biyogaz Potansiyeli Hesaplamasında Kullanılacak Teknik Veriler

\begin{tabular}{|c|c|c|c|c|c|c|c|}
\hline & Hayvan Cinsi & $\begin{array}{c}\text { Yaş Gübre } \\
\text { Miktarı } \\
\text { kg/gün }\end{array}$ & $\begin{array}{c}\text { Elde } \\
\text { Edilme } \\
\text { Oranı }\end{array}$ & 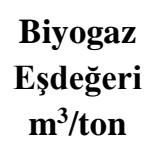 & $\begin{array}{c}\text { Isıl } \\
\text { Eşdeğeri } \\
\mathbf{M J} / \mathbf{m}^{3}\end{array}$ & $\begin{array}{c}\text { Elektriksel } \\
\text { Eşdeğeri } \\
\text { kWh/m } \mathbf{m}^{3}\end{array}$ & $\begin{array}{c}\text { TEP } \\
\text { 1/MJ }\end{array}$ \\
\hline \multirow{5}{*}{ Büyükbaş } & Inek & 58 & 0,84 & 33 & \multirow{11}{*}{22,5} & \multirow{11}{*}{2,29} & \multirow{11}{*}{$23,8846.10^{-5}$} \\
\hline & $B o \breve{g} a$ & 42 & 0,84 & 33 & & & \\
\hline & Tosun & 37 & 0,84 & 33 & & & \\
\hline & Düve & 24 & 0,84 & 33 & & & \\
\hline & Buză̆g & 12 & 0,84 & 33 & & & \\
\hline \multirow{2}{*}{ Küçükbaş } & Koyun-Keçi (yetişkin) & 2 & 0,50 & 58 & & & \\
\hline & Koyun-Keçi (yavru) & 1,2 & 0,50 & 58 & & & \\
\hline \multirow{4}{*}{ Kümes hayvanı } & Broiler & 0,19 & 0,99 & 78 & & & \\
\hline & Yumurta tavuğu & 0,13 & 0,99 & 78 & & & \\
\hline & Hindi & 0,38 & 0,99 & 78 & & & \\
\hline & Ördek & 0,33 & 0,99 & 78 & & & \\
\hline
\end{tabular}

\section{Araştırma Sonuçları ve Tartışma}

Balıkesir iline ait hayvansal kaynaklı biyogaz potansiyelinin hesabı için öncelikle Balıkesir genelindeki hayvan sayılarına ve önceki bölümde verilen kabullere dayanılarak toplam gübre miktarı aşağıdaki denklem ile hesaplanmıştır.

$$
T G M=H S . E E O . Y G M \cdot \frac{365}{1000}
$$

Denklemde TGM (toplam gübre miktarı) ton/yıl olarak bir yılda hayvanlardan elde olunacak yaş gübre miktarını, HS (hayvan sayısı) il genelindeki toplam hayvan sayısını, EEO (elde edilme oranı) yüzde olarak hayvanlardan elde olunabilecek yaş gübre oranını, 
YGM (yaş gübre miktarı) kg/hayvan-gün bir günde bir hayvan tarafından üretilen yaş gübre miktarını, göstermektedir. Tablo 3 'te hayvan cinslerine göre elde edilebilir toplam yaş gübre miktarları hesaplanmıştır.

Tablo 3. Hayvan Cinslerine Göre Yaş Gübre Miktarları

\begin{tabular}{|c|c|c|c|c|c|}
\hline & Hayvan Cinsi & $\begin{array}{c}\text { Toplam Hayvan } \\
\text { Sayısı (adet) }\end{array}$ & $\begin{array}{c}\text { Hayvan Sayısı } \\
\text { (adet) }\end{array}$ & $\begin{array}{c}\text { Toplam Gübre } \\
\text { (ton/yıl) }\end{array}$ & $\begin{array}{c}\text { TOPLAM } \\
\text { (ton/yil) }\end{array}$ \\
\hline \multirow{5}{*}{ Büyükbaş } & İnek & \multirow{5}{*}{538.682} & 228.319 & 4.060 .151 & \multirow{5}{*}{6.055 .564} \\
\hline & Boğa & & 11.215 & 144.418 & \\
\hline & Tosun & & 62.041 & 703.806 & \\
\hline & Düve & & 74.697 & 549.650 & \\
\hline & Buzağ1 & & 162.410 & 597.539 & \\
\hline \multirow{2}{*}{ Küçükbaş } & Koyun-Keçi (yetişkin) & \multirow{2}{*}{1.189 .854} & 950.017 & 346.756 & \multirow{2}{*}{399.281} \\
\hline & Koyun-Keçi (yavru) & & 239.837 & 52.524 & \\
\hline \multirow{4}{*}{ Kümes hayvanı } & Broiler & \multirow{4}{*}{33.218 .109} & 26.160 .569 & 1.796 .093 & \multirow{4}{*}{2.142 .600} \\
\hline & Yumurta tavuğu & & 6.868 .436 & 322.648 & \\
\hline & Hindi & & 72.446 & 9.948 & \\
\hline & Ördek & & 116.658 & 13.911 & \\
\hline
\end{tabular}

Balıkesir 2018 İl Tarım ve Orman Müdürlüğü verilerine göre Türkiye genelindeki iller arasında, büyükbaş hayvan sayısında 5.sırada, et tavuğu sayısında 3. ve yumurta tavuğu sayısında 5. sırada bulunmaktadır (BİTOM, 2019). Şekil 2'den görüleceği üzere Balıkesir il genelindeki elde edilebilir toplam yaş gübre miktarı \%70 oranında büyükbaş hayvan kaynaklıdır. Ancak Balıkesir broiler ve yumurta tavukçuluğunda Türkiye'nin önde gelen illerinden olması hasebiyle $\% 25$ gibi önemli miktarda kümes hayvanı gübresine de sahiptir.

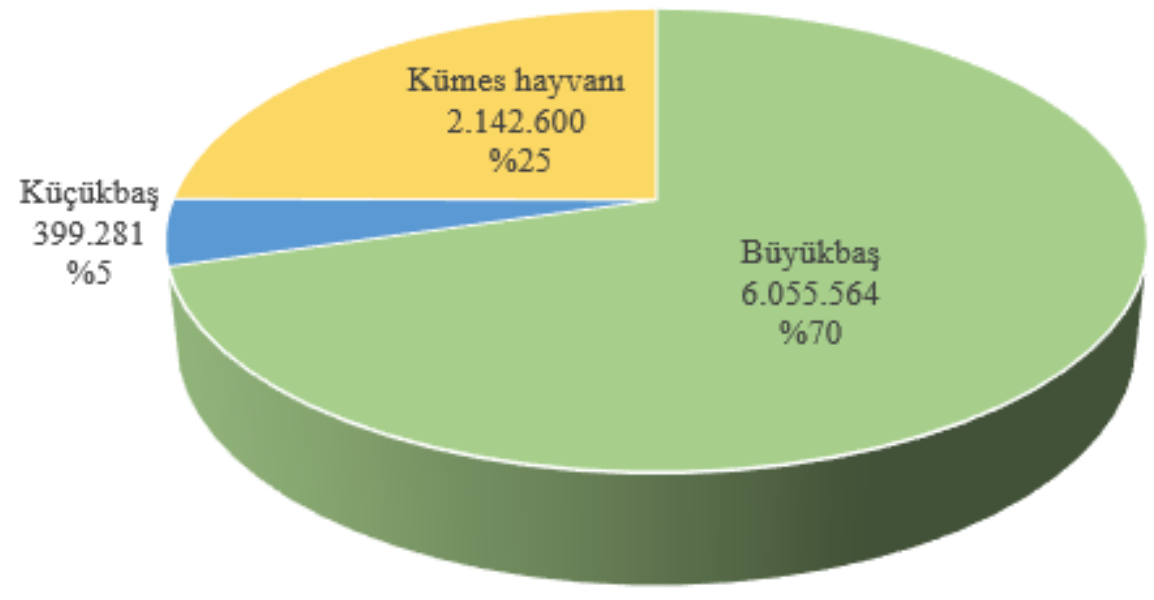

Şekil 2. Il Genelindeki Toplam Yaş Gübre Dağılımı

Toplam gübre miktarı hesaplandıktan sonra tablo 2'de ki kabuller kullanılarak toplam biyogaz potansiyeli ve bu gazın 1sıl, elektriksel ve TEP eşdeğerleri Tablo 4’te hesaplanmıştır.

Tablo 4. Toplam Biyogaz Potansiyeli ve Enerji Eşdeğeri

\begin{tabular}{l|r|r|r|r|r}
\hline & \multicolumn{1}{|c|}{$\begin{array}{c}\text { Gübre } \\
\text { (ton/yıl) }\end{array}$} & $\begin{array}{c}\text { Biyogaz Eşdeğeri } \\
\left(\mathbf{m}^{\mathbf{3}} / \mathbf{y l l}\right)\end{array}$ & $\begin{array}{c}\text { Isll Eşdeğeri } \\
\text { (MJ/yl) }\end{array}$ & $\begin{array}{c}\text { Elektriksel Eşdeğeri } \\
\text { (MWh/yıl) }\end{array}$ & \multicolumn{1}{c}{ TEP } \\
\hline Büyükbaş & 6.055 .564 & 199.833 .612 & 4.496 .256 .270 & 457.619 & 107.391 \\
\hline Küçükbaş & 399.281 & 23.158 .298 & 521.061 .705 & 53.033 & 12.445 \\
\hline Kümes hayvanı & 2.142 .600 & 167.122 .800 & 3.760 .263 .000 & 382.711 & 89.812 \\
\hline TOPLAM & 8.597 .445 & 390.114 .710 & 8.777 .580 .975 & 893.363 & 209.649 \\
\hline
\end{tabular}

Bilindiği üzere her hayvan türünün farklı biyogaz üretebilme potansiyeli vardır. Bu kapsamda hayvan sayıları ve hayvan gübrelerinin toplam miktarları üzerinden bir karşılaştırma doğru bir değerlendirme yapmaya engeldir. Bu sebeple hayvan türlerine göre elde olunabilecek biyogaz miktarları üzerinden bir değerlendirme Şekil 3'de gösterilmiştir. Bu sonuçlara göre Balıkesir ilinde hayvansal kaynaklı biyogaz potansiyelinin \%51'i büyükbaş hayvanlar, \%43’ü kümes hayvanları, \%6'sı da küçükbaş hayvanlarından elde edilebilecek atıklardan oluşmaktadır. 


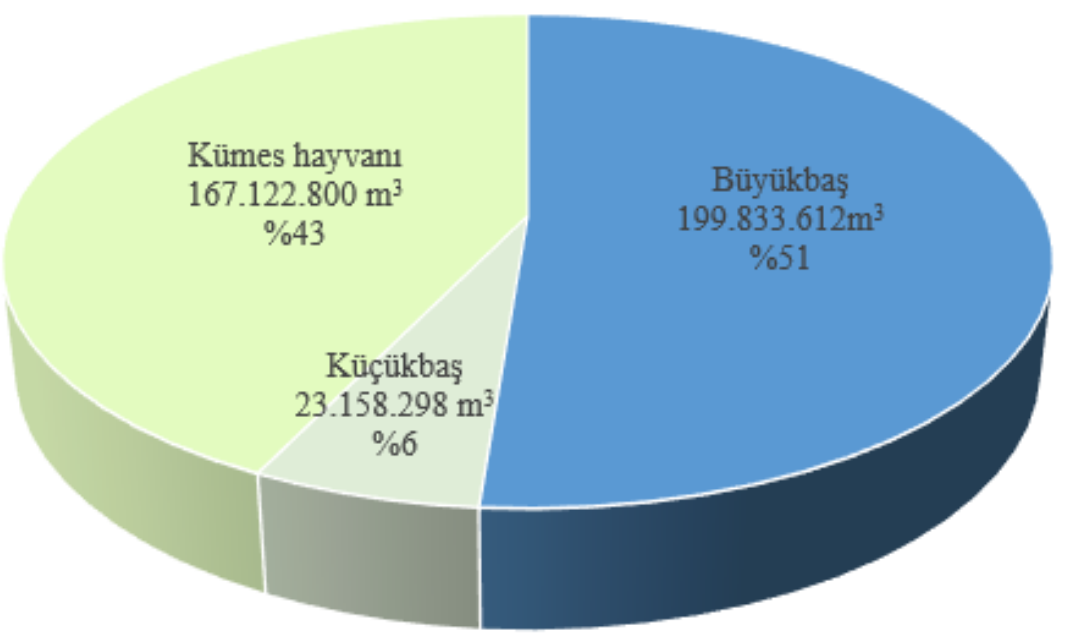

Şekil 3. Kaynaklara Göre Biyogaz Potansiyeli Dă̆llımı

Balıkesir, Tablo 4'e göre, yıllık 893.393 MWh sadece hayvansal atık kaynaklı biyogazdan elektrik enerjisi üretim potansiyeline sahiptir. Bir elektrik santralinin yılda 8.000 saat çalışacağı düşünüldüğünde 112 MW'lık bir BES kurulabilir.

Enerji ve Tabii Kaynaklar Bakanlığı tarafından hazırlanan Türkiye Biyokütle Enerjisi Potansiyel Atlasına göre Balıkesir ilinde biyokütle kaynaklı toplam kurulu gücü 35,75 MW 3 adet lisanslı biyokütle elektrik santrali bulunmaktadır. Bu santrallerin 1 tanesi Bandırma diğerleri Gönen ilçesi sınırlarında bulunmaktadır. Santraller tarımsal ve hayvansal atıkların birlikte kullanıldığı santrallerdir. 30 MW ile en büyük kurulu güce sahip olan santral, sadece orman atıklarından elektrik üretmektedir [9]. Halihazırda çeşitli güçlerde inşa halinde olan toplamda 4,55 MW'lık 4 adet hayvansal atık kullanacak biyogaz elektrik santralı vardır. Sonuç itibariyle Balıkesir il sınırları dahilinde toplam biyogaz elektrik santralı potansiyeli 112 MW iken bunun sadece 10,30 MW'lık yaklaş1k \%10'luk bir kısmı kullanılabilir durumdadır.

Güney marmara kalkınma ajansı tarafından hazırlanan 2017 Yılı Eylem Planında Balıkesir ili toplam biyogaz potansiyeli yaklaşık $800.000 \mathrm{~m}^{3}$ /gün olarak belirlenmiştir (GMKA, 2017). Yapmış olduğumuz hesaplamalara göre 2018 y1lı için bu rakam 1.068 .807 $\mathrm{m}^{3}$ /gün olarak tahmin edilmiştir.

Balıkesir ilinde, büyükbaş hayvan varlığının en yüksek olduğu ilçe 117.923 adet hayvan ve \%21,9'lik oran ile Merkez Altıeylül ve Karesi ilçeleridir. İlçelerin hayvan yoğunlukları değerlendirilirken gübre toplanabilirliği ve taşınabilirliği açısından 20 baş ve üstü ile 50 baş ve üstü ayrı ayrı dikkate alınmıştır. Bu kapsamda 20 baş ve üzeri hayvana sahip işletmelerin toplam hayvan varlığ ve Erdek ilçeleri haricinde her ilçe için 1000'in üzerindedir. Dursunbey ve İvrindi ilçelerinde 20 baş ve üzeri büyükbaş hayvan varlığı 1000'den fazla olmasına rağmen bu ilçedeki büyükbaş hayvanların \%72-78'i 20 baş altında olup aile işletmelerinde bulunmaktadır. 50 baş ve üzeri hayvan varlığ 1 olan işletmelere göre değerlendirdiğinde Marmara, Erdek ve Gömeç ilçeleri haricinde bütün ilçelerde 1000 'in üzerindedir. İl genelinde 20 baş ve üzeri hayvana sahip işletmelerdeki hayvan sayısı toplam hayvan sayısının \%56'sı iken, 50 baş ve üzeri hayvana sahip işletmelerdeki hayvan sayısı \%27'ye karşılık gelmektedir. Daha çok sayıda hayvana sahip işletmelerdeki atıkların toplanması ve taşınması daha kolay ve ekonomik olmaktadır.

Balıkesir ilinde küçükbaş hayvan varlığının en yüksek olduğu ilçe 265.909 adet hayvan ve \%22,3'lük oran ile Merkez Altıeylül ve Karesi ilçeleri, en az olduğu ilçe 9.357 adet hayvan ve \%0,78'lik oran ile Erdek ilçesidir. Balıkesir ilinde kümes hayvan varlığının en yüksek olduğu ilçe 8.138.351 adet hayvan ve \%24,4'lük oran ile Bandırma ilçesi, en az olduğu ilçe 630 adet hayvan ve \%0,002'lik oran ile Marmara ilçesidir.

\section{Sonuç}

Ülkemizde nüfus artışına bağlı olarak artan hayvancılık faaliyetleri geleneksellikten entansif hayvancılık faaliyetlerine evrilmiş durumdadır. Bugüne kadar aile işletmelerinde yapılan hayvancılık faaliyetleri sonucunda ortaya çıkan atıklar, doğal gübre olarak araziye atılarak bertaraf edilmektedir. Ancak çok sayıda hayvana sahip entansif çiftliklerde ortaya çıkan büyük miktarda atıklar doğaya olan olumsuz etkileri kadar yerüstü ve yer altı suları içinde önemli bir kirletici kaynağıdır. Dolayısıyla büyük ölçekli hayvancılık işletmeleri kurulurken bu tesislerin ortaya çıkardığı atıkların bertaraf konusu da planlamalara dahil edilmelidir. Bu amaçla büyük ölçekli yetiştiricilik yapılan tesislerin yakınlarında biyogaz elektrik santrallerinin de birlikte kurulumu teşvik edilmelidir.

Balıkesir genelinde 112 MW'lık bir biyogaz elektrik santralı potansiyeli bulunmaktadır. Bu rakam Türkiye'nin mevcut biyokütle kurulu gücünün \%17'sine karşılık gelmektedir. Halihazırda çalışan ve inşa edilen santraller ile bu potansiyelin \%10,3 gibi çok küçük bir kısmı değerlendirilmektedir. Balıkesir il genelinde 2018 yılı verilerine göre 50 baş ve üzeri büyükbaş hayvana sahip toplam 1.383 işletmede 138.610 sığır bulunmaktadır. Bu işletmeler Bandırma-Gönen ve Altıeylül-Karesi-Bigadiç-Susurluk ilçelerinde yoğunlaşmıştır. Aynı şekilde Ayvalık-Gömeç-Edremit-Havran-Marmara ilçeleri haricindeki bütün ilçelerde 130.000 ve üzerinde kümes hayvanı bulunmaktadır. Dolayısıyla büyük miktarlardaki bu hayvansal atıkların hem çevre kirliliği yapmaması hem de yerli ve yenilenebilir bir enerji kaynă̆ı olarak ülkemiz ekonomisine kazandırılması büyük önem arz etmektedir. 


\section{Kaynakça}

Abade, C.C., Fregonesi, J.A., Von Keyserlingk, M.A.G. \& Weary, D.M. (2015). Dairy Cow Preference And Usage Of An Alternative Freestall Design. Journal Dairy Science, 98(2), 960-5.

ASAE, (2005). Manure Production and Characteristics. ASAE Standard, March (D384.2), 1-19.

Başçetinçelik, A., Öztürk, H.H., Karaca, C., Kaçıra, M., Ekinci, K., Kaya, D., Baban, A., Güneş, K., Komitti, N., Barnes, I. \& Nieminen, M. (2003). A Guide on Exploitation of Agricultural Residues in Turkey. LIFE03TCY/TR/000061, ANNEX 14 Final Report.

Bayrak Işıı, E.H., Polat, F. (2018). The Biogas Potential That Can Be Obtained From The Animal Wastes Of Tokat Province. Gaziosmanpasa Journal of Scientific Research, 7(3), 93-100.

BBB, (2019). Balıkesir Büyükşehir Belediyesi, Nazım İmar Planı Plan Açılama Raporu, https://www.balikesir.bel.tr/documents/imar/2019/haziran/25.05.2019/4/5000Rapor.pdf Erişim Tarihi: 15 Haziran 2019.

BíTOM, (2019). Balıkesir İl Tarım Ve Orman Müdürlüğ̈̈, 2018 Y1lı Faaliyet Raporu.

Bond, T. \& Templeton, M.R. (2011). History And Future Of Domestic Biogas Plants İn The Developing World. Energy Sustainable Development, 15(4), 347-354.

Cantrell, K. B., Ro, K. S., Szögi, A. A., Vanotti, M. B., Smith, M. C., \& Hunt, P. G. (2012). Green Farming Systems for The Southeast USA Using Manure-to-Energy Conversion Platforms. Journal of Renewable and Sustainable Energy, 4(4), 1-12.

Çağlayan, G. H., \& Koçer, N. N. (2014). Muş İlinde Hayvan Potansiyelinin Değerlendirilerek Biyogaz Üretiminin Araştırılması. Muş Alparslan Üniversitesi Fen Bilimleri Dergisi, 2(1), 215-220.

Division, S. C. A. (2019). A geographical profile of livestock manure production in Canada 2006. http://www.statcan.gc.ca/pub/16002-x/2008004/article/10751-eng.htm\#a3 Erişim Tarihi: 25 Haziran 2019.

EiDKKYB, (2019). Eskişehir İli Damızlık Koyun Keçi Yetiştiricileri Birliği, http://eskisehirkoyunkeci.org/?page id=18 Erişim Tarihi: 15 Haziran 2019.

EIGGM, (2019). Enerji İşleri Genel Müdürlüğ̈̈, http://www.yegm.gov.tr/yenilenebilir/biyogaz.aspx Erişim Tarihi: 25 Haziran 2019.

Ekinci, K., Külcü, Kaya, R.D., Yaldız, O., Ertekin, C. \& Öztürk, H.H. (2010). The Prospective Of Potential Biogas Plants That Can Utilize Animal Manure İn Turkey. Energy Exploration \& Exploitation, 28(3), 187-206.

ETKB, (2019). Enerji ve Tabii Kaynaklar Bakanlığı, Türkiye Biyokütle Enerjisi Potansiyel Atlası, http://bepa.yegm.gov.tr/ Erişim tarihi: 15 Temmuz 2019.

Gamal-El-Din, H. (1986). Biogas Production from Antibiotic-Contaminated Cow Manure. Biogas Technology, Transfer and Diffusion, 7, 480-487.

GMKA, (2012). Güney Marmara Kalkınma Ajansı, Bandırma Koyunculuk Araştırma İstasyonu Müdürlüğü, Balıkesir İlinin Organik Büyükbaş ve Küçükbaş Hayvancılık Olanaklarının Belirlenmesi.

GMKA, (2017). Güney Marmara Kalkınma Ajansı. Balıkesir Yatırım Destek Ve Tanıtım Stratejisi (2017-2023) Ve 2017 Yılı Eylem Plani.

GMKA, (2019). Güney Marmara Kalkınma Ajansı, Balıkesir Tarım ve Hayvancılık Yatırım Rehberi.

Gülen, J., \& Arslan, H. (2005). Biyogaz. Journal of Engineering and Natural Sciences Mühendislik ve Fen Bilimleri Dergisi, 4, $121-$ 129.

Hayvansal Atıkların Biyogaz Yoluyla Kaynak Verimliliği Esasında ve İklim Dostu Kullanımı Projesi, Türk-Alman Biyogaz Projesi. T.C. Çevre ve Şehircilik Bakanlığı.

Kaya, D., Çağman, S., Eyidoğan, M., Aydöner, C., Çoban, V. \& Tırıs, M. (2009). Türkiye'nin Hayvansal Atık Kaynaklı Biyogaz Potansiyeli ve Ekonomisi. Atık Teknolojileri Dergisi, (1), 48-51.

Massé, D.I., Saady, N.M.C., Gilbert, Y. (2014). Potential of Biological Processes to Eliminate Antibiotics in Livestock Manure: An Overview. Animals, 4(2), 146-163.

McKendry, P (2002). Energy Production From Biomass (part 1): Overview of Biomass. Bioresource Technology, 83 (1), 37-46.

Montzka, S. A.; Dlugokencky, E. J. \& Butler, J. H. (2011). Non-CO2 Greenhouse Gases And Climate Change. Nature, 476(7358), $43-$ 50.

NRCS, (2019a). The U.S. Department of Agriculture Natural Resources Conservation Service (NRCS). https://lpelc.org/animalagriculture-in-the-u-s-trends-in-production-and-manure-management/ Erişim Tarihi: 17 Haziran 2019.

NRCS, (2019b). The U.S. Department of Agriculture Natural Resources Conservation Service (NRCS). https://www.nrcs.usda.gov//wps/portal/nrcs/detail/null/?cid=nrcs143 014211 Erişim Tarihi: 25 Haziran 2019.

Ogejo, J., Wen, Z., Ignosh, J., Bendfeldt, E., \& Collins Jr., E. (2009). Biomethane Technology. Virginia Cooperative Extension, (Publication 442-881), 1-11.

P. J. Magistretti, A. A., Pellerin, L., Rothman, D. L. \& Shulman, R. G. (1999). Energy on Demand. Science (80-. )., 283 (5401), $496-$ 497.

Salihoğlu, N.K., Teksoy, A. \& Altan, K. (2019). Büyükbaş Ve Küçükbaş Hayvan Atıklarından Biyogaz Üretim Potansiyelinin Belirlenmesi: Balıkesir İli Örneği. Ömer Halisdemir Üniversitesi Mühendislik Bilimleri Dergisi, 8(1), 31-47.

Solomie, A.G., Miranda, P.M.M. \& Alfons, G.J.M. (2010). Costs of Producing Biogas at Dairy Farms in The Netherlands. Int. J. Food System Dynamics, (1), 26-30.

Sözer, S. \& Yaldız, O. (2011). Muz Serası Atıkları ve Sığır Gübresi Karışımlarından Mezofilik Fermantasyon Sonucu Üretilebilecek Biyogaz Miktarının Belirlenmesi Üzerine Bir Araştırma. Akdeniz Üniversitesi Ziraat Fakültesi Dergisi, 4 (2), $75-78$.

S.N., (2012). Statistics Netherlands. Standardised Calculation Methods For Animal Manure And Nutrients. 
Straße, T. \& Ertem, F.C., (2011). Türkiye'de Biyogaz Yatııımları İçin Geçerli Koşulların ve Potansiyelin Değerlendirilmesi. Türkiye'de Hayvansal Atıkların Biyogaz Yoluyla Kaynak Verimliliği Esasında ve İklim Dostu Kullanımı Projesi, Türk-Alman Biyogaz Projesi. T.C. Çevre ve Şehircilik Bakanlığı,.31.

Suganthi, L., \& Samuel, A. A. (2012). Energy Models For Demand Forecasting - A review. Renewable and Sustainable Energy Reviews.

TEİAŞ, (2018). Türkiye Elektrik İletim A.Ş. Genel Müdürlüğü. Türkiye Elektrik Enerjisi 5 Ylllık Üretim Kapasite Projeksiyonu (2018-2022).

TÜIK, (2019). 2018 Yılı Balıkesir Hayvancılık İstatistikleri, https://biruni.tuik.gov.tr/medas/?locale=tr Erişim Tarihi: 15 Haziran 2019.

TÜSİAD, (2011). Vizyon 2050 Türkiye, no. TÜSİAD-T/2011-09/518.

WEC, (2013). World Energy Scenarios: Composing Energy Futures To 2050. Report, 1-288.

Wuebbles, D. (2002). Atmospheric Methane And Global Change. Earth-Science Reviews, (57), 177-210.

Yaldız, O., Weckenmann, D., \& Öchsner, H. (1998). Sürekli Akışlı Bir Biyogaz Tesisi Ve Gaz Motorunda Enerji Üretiminin İrdelenmesi. Tarımsal Mekanizasyon 18. Ulusal Kongresi.

Yılmaz, A. (2019). Türkiye'de Biyogaz Üretimi ve Kurulu Santrallerin Ürettiği Elektrik Eneriisi. Ecological Life Sciences (NWSAELS), 14(1), 12-28. 